\title{
Trainee focus
}

\section{Maximising direct observation of procedural skills for learning in the emergency department}

\author{
Victor Lee \\ Department of Emergency Medicine, Austin Hospital, Melbourne, Victoria, Australia
}

Correspondence: Dr Victor Lee, Department of Emergency Medicine, Austin Hospital, 145 Studley Road, Heidelberg, VIC 3084, Australia. Email: Victor.Lee@austin.org.au

Victor Lee, MBBS, MHPE, FACEM, Senior Staff Specialist, Co-Director of Emergency Medicine Training.

Competing Interests: VL is deputy chair of the Central WBA Panel and Education and Training section editor for EMA

Jack is an early phase advanced trainee who has just asked me to do an intercostal catheter (ICC) insertion direct observation of procedural skills (DOPS) with him. He tells me he has only watched one and done another under close supervision before. Of course, it is a busy Monday shift but I've managed to set aside time to observe him and provide him with feedback.

Preparation is the key so that we maximise our time and are not off the floor for too long. This also sets up a protected learning environment for making Jack's DOPS as specific and useful to him as possible. The first task would be to make sure I do not get interrupted during the time I am supervising him. Secondly, preparing the patient, staff and equipment minimises unnecessary breaks to go fetch missing equipment or reposition the patient. Much of this can be planned beforehand rather than me just stepping into the resuscitation cubicle to fill in a form, rush out to perform an unrelated task, then returning and giving Jack feedback. Next, there are three important considerations to maximise the DOPS for learning and feedback and these are: learning conditions, learning cues and deliberate practice. ${ }^{1,2,3}$

\section{Learning Conditions}

Learning conditions can be divided into the trainee's learning preference and learning autonomy. ${ }^{4}$

This is the author manuscript accepted for publication and has undergone full peer review but has not been through the copyediting, typesetting, pagination and proofreading process, which may lead to differences between this version and the Version of Record. Please cite this article as doi: 10.1111/1742-6723.12928

This article is protected by copyright. All rights reserved. 
Understanding Jack's learning preference means knowing what Jack wants to get out of inserting this ICC. We often do not check with our trainees what they most want and need before launching head first into a procedure or task. That makes it confusing for both the trainee and supervisor. Aligning goals and purpose is vital to achieving stated outcomes and making feedback more direct and meaningful. ${ }^{5}$ This is the concept of collaborative learning or an educational alliance. ${ }^{6}$ This allows trainees to show insight into what their shortcomings may be and for the supervisor to then focus on those aspects and pay dutiful attention, making their feedback more credible to the trainee. And this provides the opportunity for trainees to directly input into their learning from the outset. This can then translate into a more focused assessment of competency which may carry more immediate relevance for future practice.

Another important preparatory step is to allow Jack to demonstrate his own autonomy and determine when he would want me to intervene (threshold point). In other words, at what stage would he want me to don my sterile gloves and help him out. My comfort level is different to his own level and unless we check this beforehand I may intervene too early and not enable him to act autonomously. Trainees often complain that their consultant jumped in too early and become frustrated that they actually would have managed if it hadn't been for a premature intervention. Conversely, some consultants would argue that they were concerned about a patient safety issue. However, that stepping in by the consultant may also be a reflection of their own discomfort, internal bias and thresholds for that particular procedure, based on a previous bad supervisory experience or lack of time. We can manage this issue by confirming the trainee's threshold point prior to embarking on and during the procedure. This prevents second guessing each other and turns the DOPS into a two-way dialogue which maximises learning.

\section{Learning Cues}

During the procedure there will be cues which Jack may use as mental prompts for his learning. ${ }^{2}$ The first is the patient's responses, both verbal and nonverbal, which Jack should take into account because this is real life and not a simulation. This can be an effective and powerful learning cue that helps shape future patient interactions when performing this procedure again. The second cue is the patient outcome and whether the chest tube was inserted safely. In most instances, the procedure succeeds and this is also another helpful motivator for future performance. Both supervisor and trainee can breathe a sigh of mutual relief but also reflect on the positive aspects of the successful procedure. The third cue will be how constructive my feedback is to Jack. Being clear and providing specific details regarding strengths and areas for further improvement can help to make this a more purposeful and credible DOPS.

\section{Deliberate Practice}

This DOPS should feed forward to Jack's next ICC insertion and remind him of the concept of deliberate practice, an essential element of mastering procedural competency. ${ }^{7}$ Deliberate practice doesn't mean repetitive practice but is premeditated and focused on performance improvement through reflecting on past 
performance. ${ }^{3}$ This is the purpose of direct observation and feedback. What can I do to get better at performing this procedure next time? Based on the targeted feedback received Jack will be able to have something to focus on for next time.

This scenario I've described is similar to a real life DOPS I have been involved in. When it is done effectively there are positives for the supervisor as well. These include refreshing your own technical skills by helping the trainee to troubleshoot a technical aspect of the procedure, jointly succeeding in performing the procedure through collaboration with the trainee and possibly even the patient, and being able to give detailed and nuanced feedback that will guide Jack's next attempt at chest tube insertion. Therefore, when done properly DOPS allows for learning through performance and can be viewed as an example of assessment as learning. Being aware of the challenging and busy environment of the Emergency Department but preparing well beforehand, checking in with the trainee and allowing time for focused attention and feedback will benefit registrars like Jack, and even supervisors like myself.

\section{References}

1. Stok-Koch L, Bolhuis S, Koopmans R. Identifying factors that influence workplace learning in postgraduate medical education. Educ Health 2007;20(1):8.

2. Watling C, Driessen E, van der Vleuten CPM, Lingard L. Learning from clinical work: The roles of learning cues and credibility judgements. Med Educ. 2012;46(2):192-200.

3. Ericsson KA. Deliberate practice and acquisition of expert performance: a general overview. Acad Emerg Med. 2008;15(11):988-94.

4. Olmos-Vega FM, Dolmans DHJM, Vargas-Castro N, Stalmeijer RE. Dealing with the tension: how residents seek autonomy and participation in the workplace. Med Educ. 2017;51(7):699-707.

5. Norcini J, Burch V. Workplace-based assessment as an educational tool: AMEE Guide No. 31. Med Teach. 2007;29(9-10):855-71.

6. Telio S, Ajjawi R, Regehr G. The "educational alliance" as a framework for reconceptualizing feedback in medical education. Acad Med. 2015;90(5):609-14.

7. Khan K, Ramachandran S. Conceptual framework for performance assessment: Competency, competence and performance in the context of assessments in healthcare - Deciphering the terminology. Med Teach. 2012 Jan;34(11):1-9. 


\section{University Library}

\section{- M M N E R VA A gateway to Melbourne's research publications}

Minerva Access is the Institutional Repository of The University of Melbourne

Author/s:

Lee, $\mathrm{V}$

Title:

Maximising direct observation of procedural skills for learning in the emergency department

Date:

2018-02-01

Citation:

Lee, V. (2018). Maximising direct observation of procedural skills for learning in the emergency department. EMERGENCY MEDICINE AUSTRALASIA, 30 (1), pp.111-112. https://doi.org/10.1111/1742-6723.12928.

Persistent Link:

http://hdl.handle.net/11343/261102 